\title{
Microfluidic Sensing System with a Multichannel Surface Plasmon Resonance Chip: Damage-Free Characterization of Cells by Pattern Recognition
}

Hiroka Sugai, ${ }^{1}$ Shunsuke Tomita, ${ }^{* 1,2}$ Sayaka Ishihara, ${ }^{1}$ Kyoko Yoshioka, ${ }^{1}$ and Ryoji Kurita ${ }^{* 1-3}$

${ }^{1}$ Health and Medical Research Institute, National Institute of Advanced Industrial Science and Technology (AIST), 1-1-1 Higashi, Tsukuba, Ibaraki 305-8566, Japan

${ }^{2}$ DAILAB, DBT-AIST International Center for Translational and Environmental Research (DAICENTER), National Institute of Advanced Industrial Science and Technology (AIST), Central 5-41, 1-1-1 Higashi, Tsukuba, Ibaraki 305-8565, Japan

${ }^{3}$ Faculty of Pure and Applied Sciences, University of Tsukuba, 1-1-1 Tennodai, Tsukuba, Ibaraki 305-8573, Japan

*Corresponding authors: s.tomita@aist.go.jp (S.T.); r.kurita@aist.go.jp (R.K.)

Supporting tables and figures

Figure S1. Schematic illustrations of the fabrication process and layout of the multichannel SPR chip $\cdots \cdots \cdots \cdots \cdot$ S-2

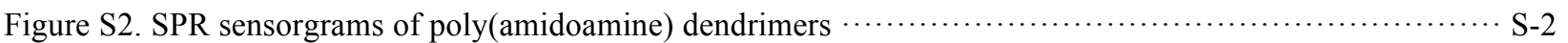

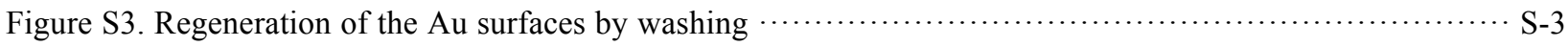

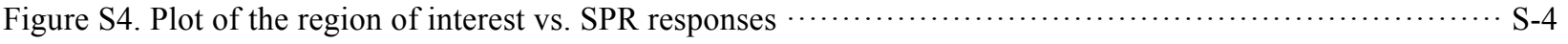

Figure S5. Pattern-recognition-based sensing of culture media from TAM-treated HepG2 cells $\cdots \cdots \cdots \cdots \cdots \cdots \cdots \cdot$.

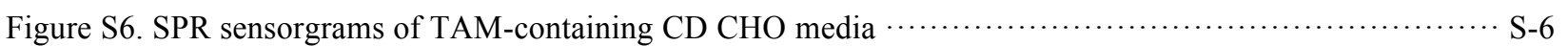

Figure S7. Correlation coefficients between discriminant scores and cell-based assays $\cdots \cdots \cdots \cdots \cdots \cdots \cdots \cdots \cdots \cdots \cdots \cdots \cdots$

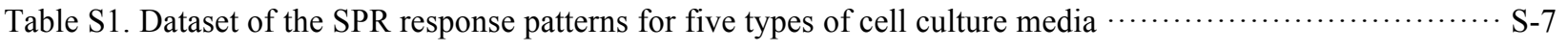

Table S2. Number of combinations achieving each accuracy in the sensing of five types of cells $\cdots \cdots \cdots \cdots \cdots \cdots \cdots+.8$

Table S3. Combinations of experimental values achieving $100 \%$ accuracy in the sensing of five types of cells $\cdots$ S- 8

Table S4. Dataset of the SPR response patterns for culture media from TAM-treated HepG2 cells $\cdots \cdots \cdots \cdots \cdots \cdots \cdot$.

Table S5. Number of combinations achieving each accuracy in the sensing of TAM-treated HepG2 cells $\cdots \cdots \cdot$. S-10

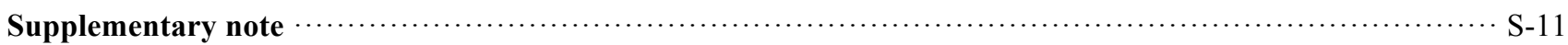

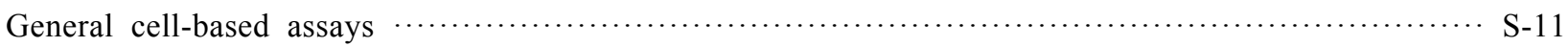

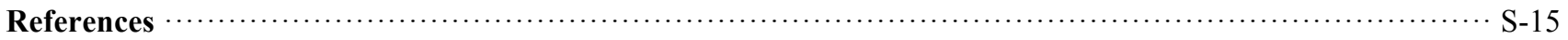




\section{Supporting tables and figures}

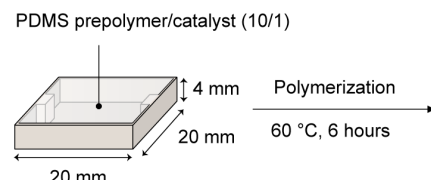
$20 \mathrm{~mm}$

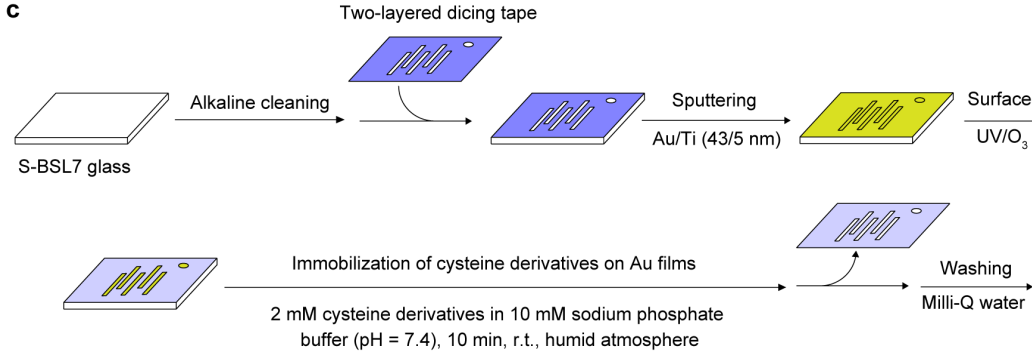
M cysteine derivatives in $10 \mathrm{mM}$ sodium phospha

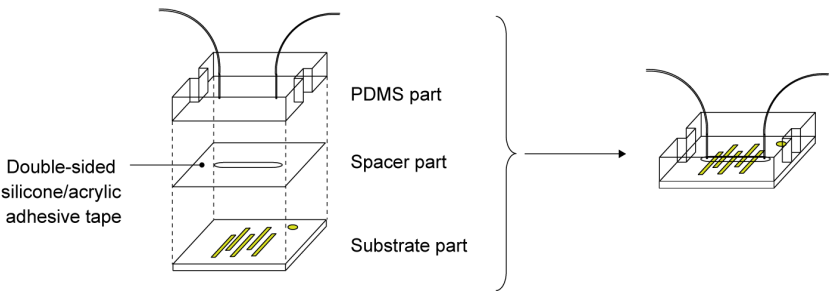

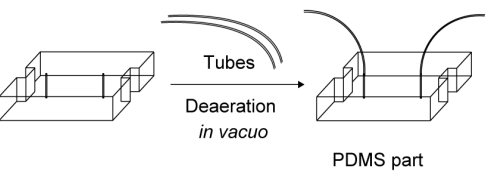

PDMS part
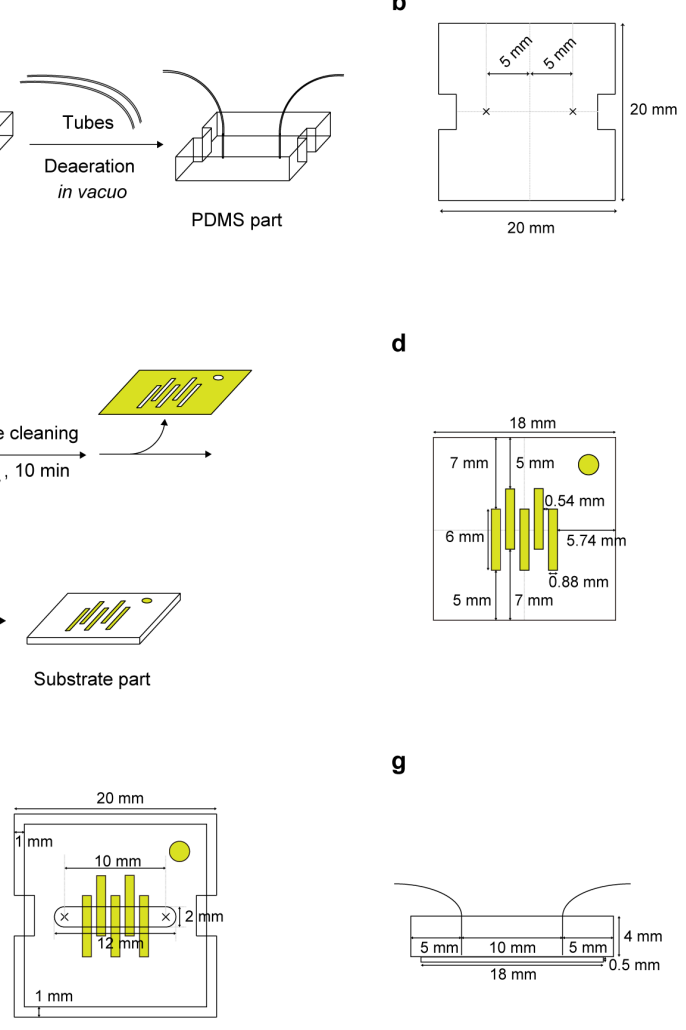

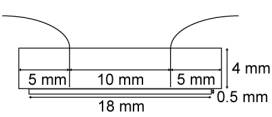

Figure S1. Schematic illustrations of the fabrication process and layout of the multichannel SPR chip. (a,c,e) Fabrication process, $(\mathrm{b}, \mathrm{d}, \mathrm{f})$ layout viewed from top and $(\mathrm{g})$ the side of $(\mathrm{a}-\mathrm{b})$ the PDMS part, $(\mathrm{c}-\mathrm{d})$ the substrate part, and $(\mathrm{e}-\mathrm{g})$ the entire chip.
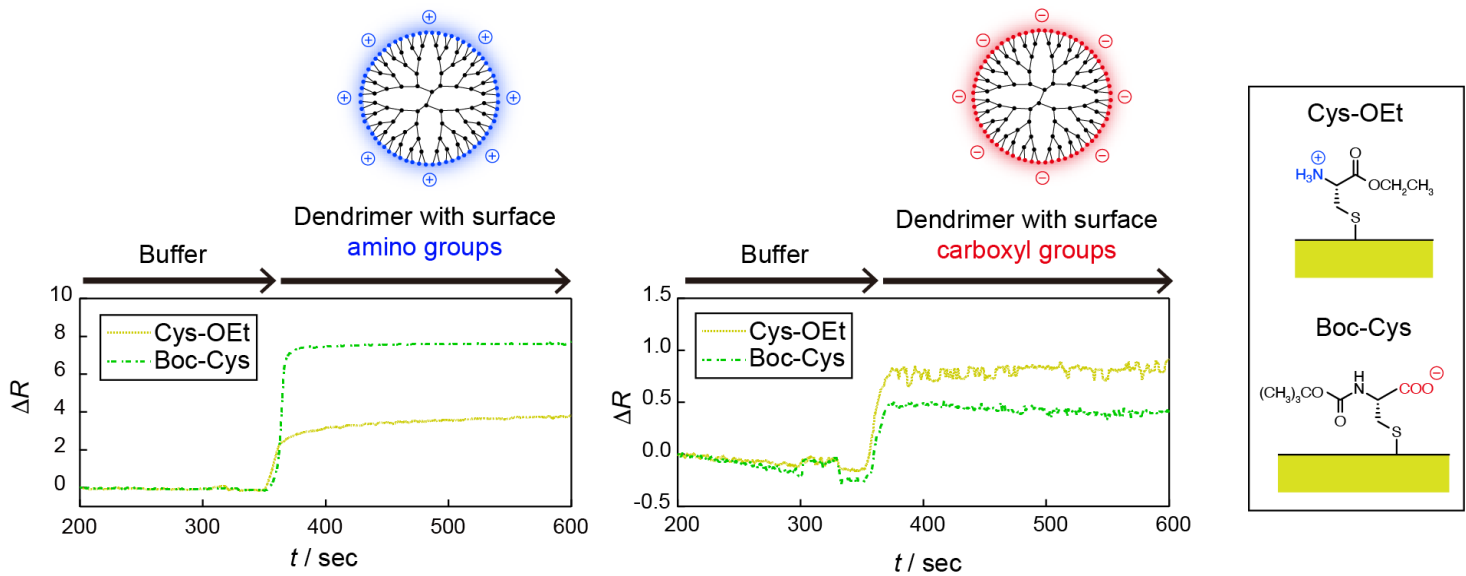

Figure S2. SPR sensorgrams between the charged dendrimers and charged cysteine derivatives on the Au surface. The SPR measurements were performed by flowing through the following solutions into a chip at a flow rate of $5.0 \mu \mathrm{L} / \mathrm{min}$ at room temperature: 1) $20 \mathrm{mM}$ sodium phosphate buffer $(\mathrm{pH}=7.0)$ with $100 \mathrm{mM} \mathrm{NaCl}$ for $5 \mathrm{~min} ; 2) 0.01 \%$ poly(amidoamine) dendrimer containing 64 surface amino or carboxyl groups (Sigma-Aldrich, Co., LLC, St. Louis, MO, USA) in $20 \mathrm{mM}$ sodium phosphate buffer $(\mathrm{pH}=7.0)$ with $100 \mathrm{mM} \mathrm{NaCl}$ for $5 \mathrm{~min}$. 
a

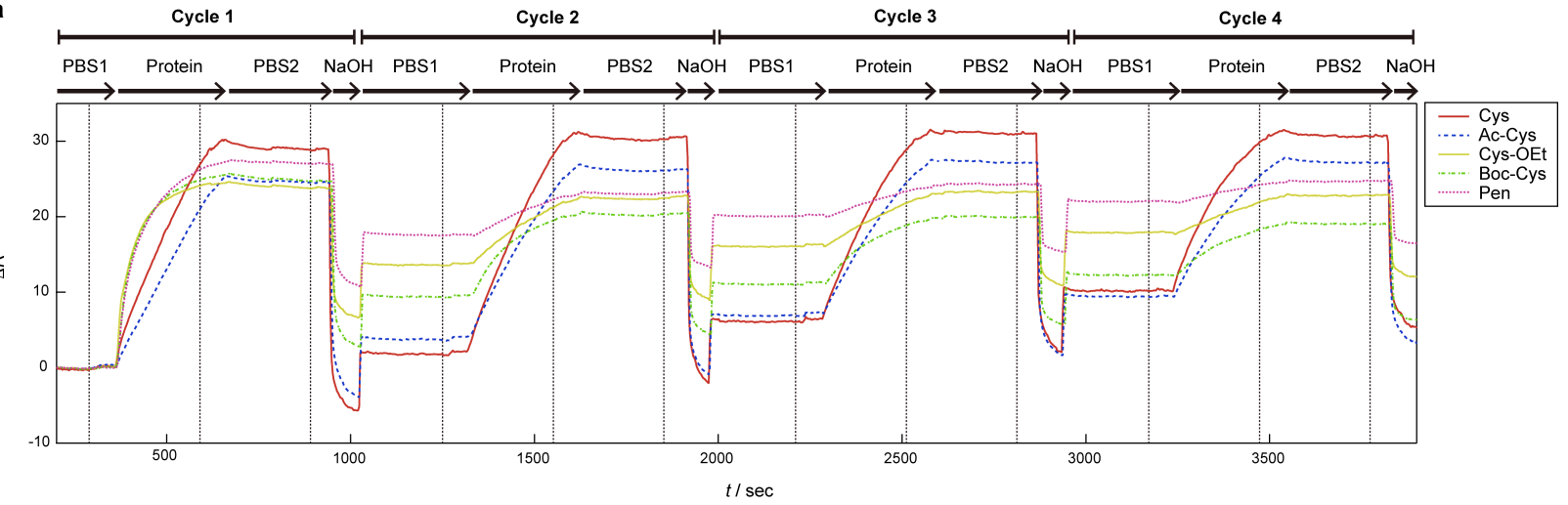

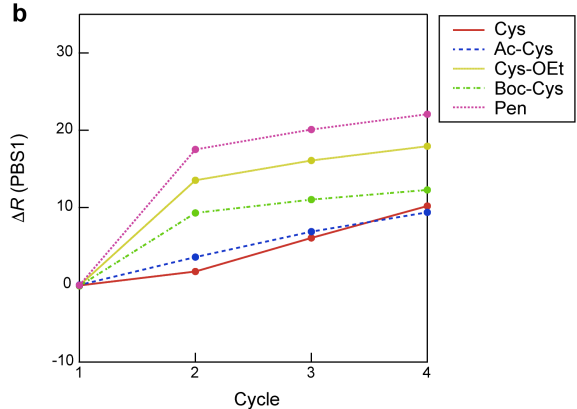

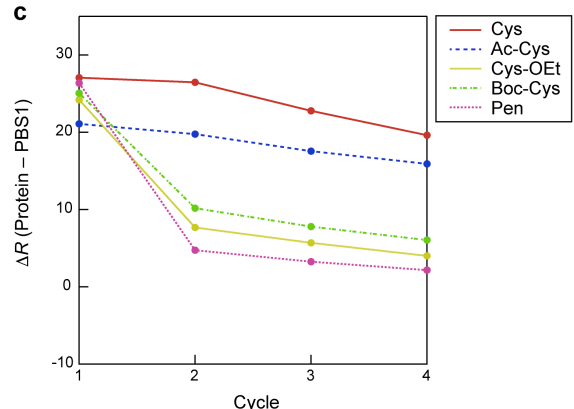

d
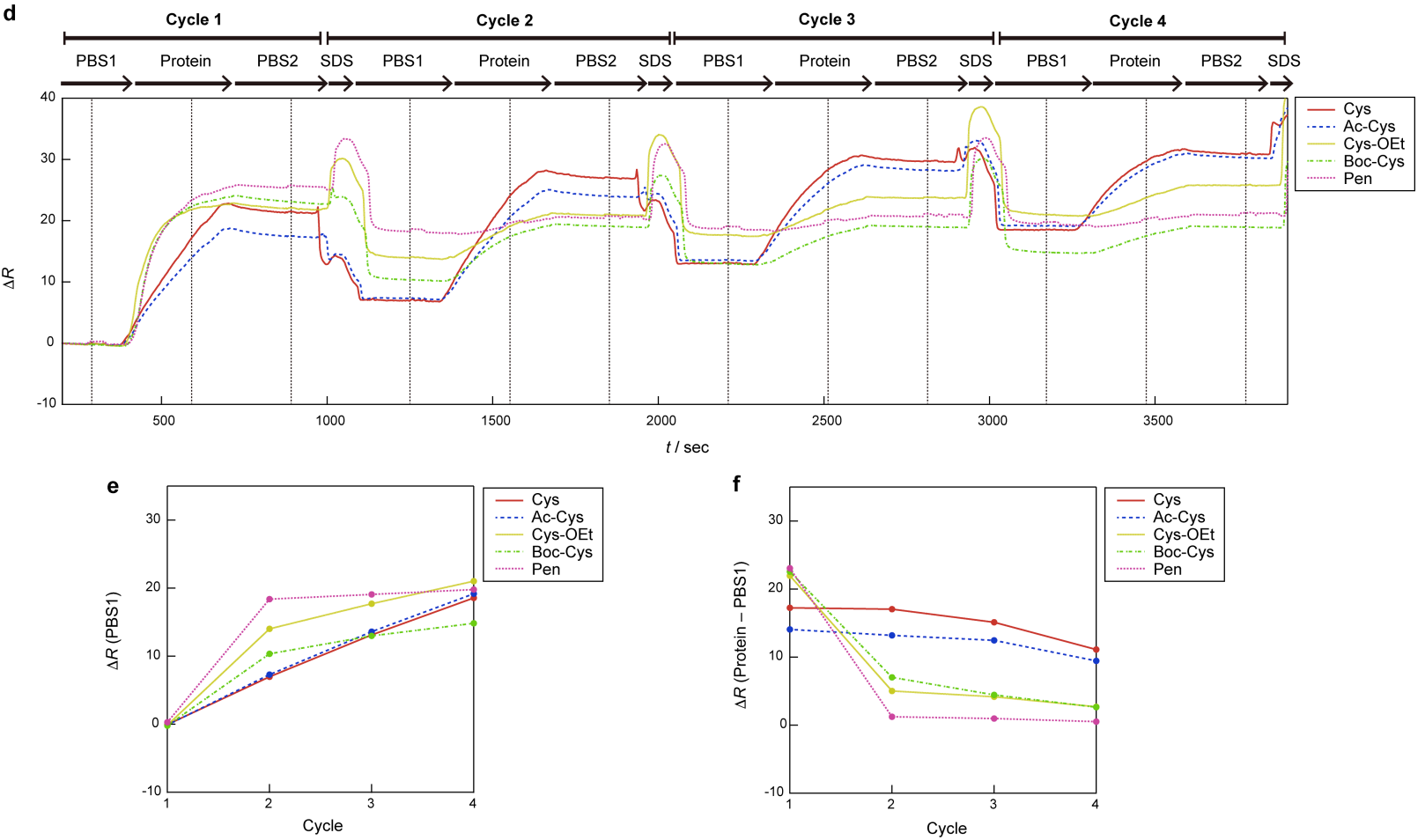

Figure S3. Regeneration of the Au surfaces by washing with $(\mathrm{a}-\mathrm{c})$ sodium hydroxide $(\mathrm{NaOH})$ or $(\mathrm{c}-\mathrm{d})$ sodium lauryl sulfate (SDS) on the SPR measurements of protein. (a, d) SPR sensorgrams. Effects of iterative measurements (b, e) on the baseline and (c, f) on the magnitudes of SPR responses of catalase. The SPR measurements were performed by flowing through the following solution into a chip at a flow rate of $5.0 \mu \mathrm{L} / \mathrm{min}$ at room temperature: 1) PBS for $5 \mathrm{~min}$; 2) $50 \mu \mathrm{g} / \mathrm{mL}$ catalase in PBS for $5 \mathrm{~min}$; 3) PBS for $5 \mathrm{~min}$; and 4) $0.5 \%$ SDS or $50 \mathrm{mM} \mathrm{NaOH}$ for $1 \mathrm{~min}$. From step 1 to 4 were repeated four times. Black dotted lines in SPR sensorgrams in (a) and (d) indicate the time at 20 sec prior to 
switching to next solution, and the value of SPR response $(\Delta R)$ at this time were used for the plot of cycle vs. $\Delta R$ in (b), (c), (e), and (f). For both washing methods, repeated measurements resulted in the increase in baseline and the decrease in the SPR responses of catalase. In addition, these changes depended on the kind of cysteine derivatives modified on the $\mathrm{Au}$ surface. This suggests that it is difficult to regenerate a chip surface completely or to predict changes in the surface conditions after washing treatment.

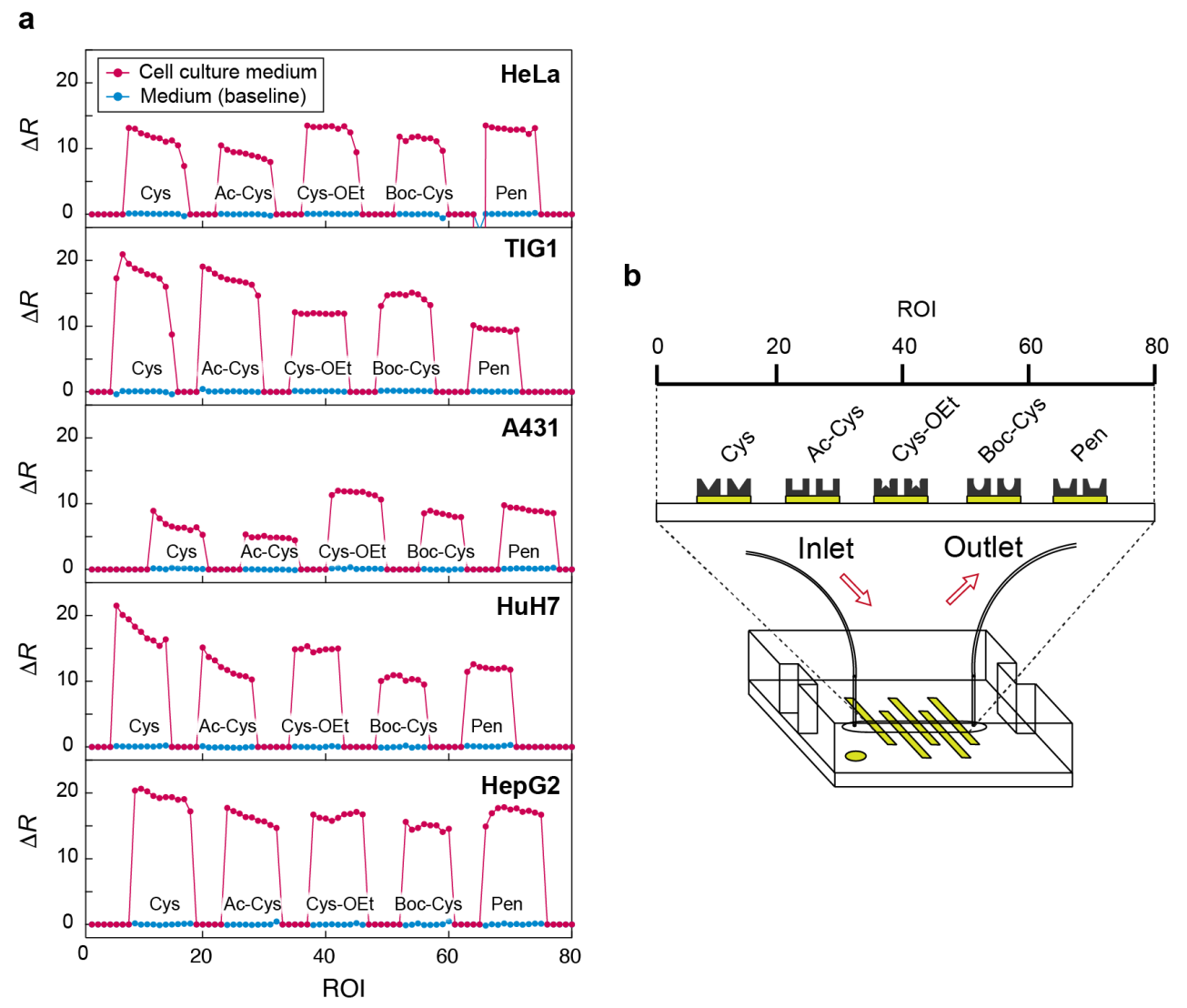

Figure S4. (a) Plot of the region of interest (ROI) vs. SPR responses. Cell culture medium and medium (baseline) correspond to the SPR responses at 280 and $580 \mathrm{sec}$ of the SPR sensorgram, respectively. (b) Definition of ROI. The detection region on the chip is divided into 80 regions, which are numbered chronologically from inlet to outlet. 
a

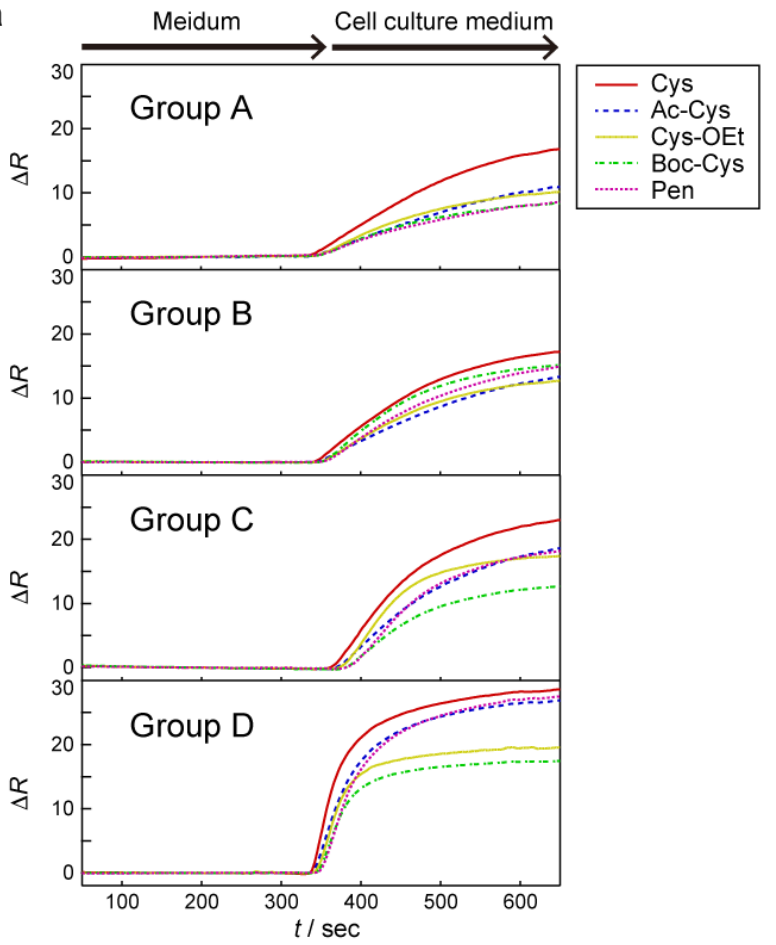

C

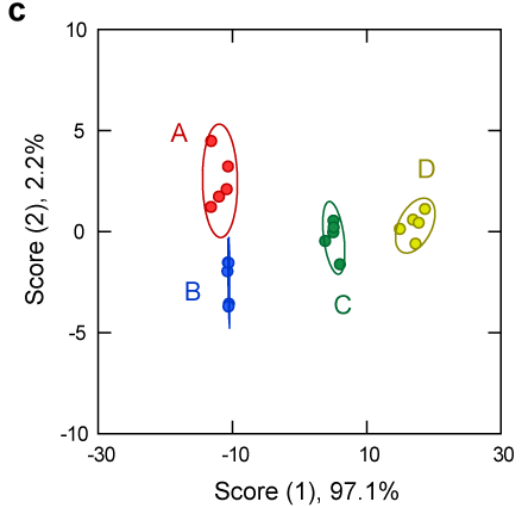

b

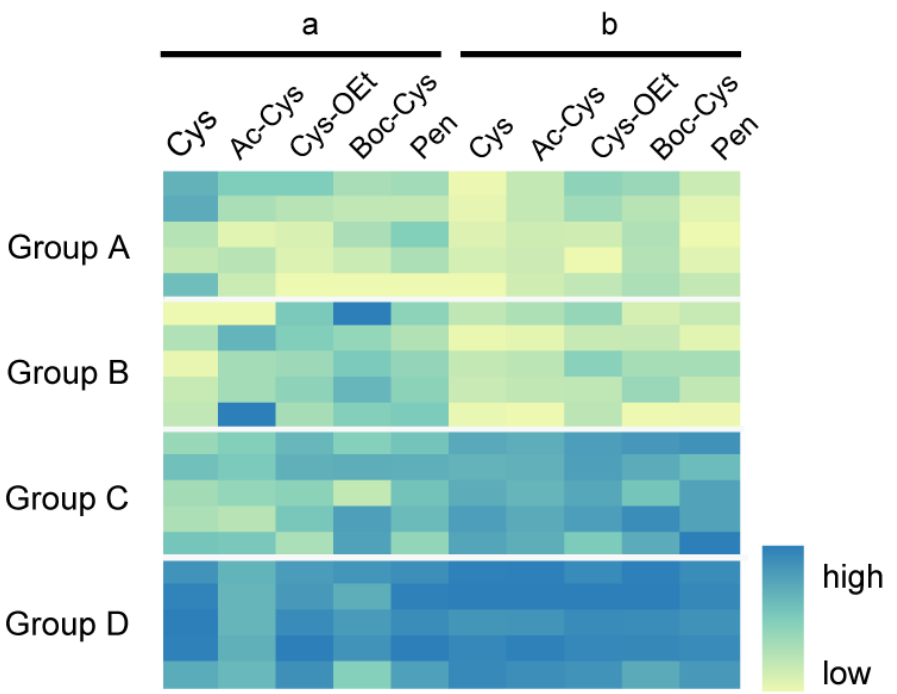

Figure S5. Pattern-recognition-based sensing of culture media from TAM-treated HepG2 cells using a multichannel SPR chip with immobilized cysteine derivatives. Groups A, B, C, and D correspond to the cell culture media of HepG2 cells treated without TAM for $0.5 \mathrm{~h}$, with $20 \mu \mathrm{M}$ TAM for $6 \mathrm{~h}$, with $40 \mu \mathrm{M}$ TAM for $12 \mathrm{~h}$, and with $70 \mu \mathrm{M}$ TAM for $12 \mathrm{~h}$, respectively. (a) SPR sensorgrams obtained from an inflow of cell culture media into a chip at a flow rate $5.0 \mu \mathrm{L} / \mathrm{min}$ for 5 min. (b) Heat map of the SPR responses $(n=5)$. (c-e) 2D discriminant score plots [(c) score (1) vs. score (2), (d) score (1) vs. score (3), and (e) score (2) vs. score (3)] obtained from the LDA of the SPR response patterns for 8 experimental values [4 probes (Cys, Ac-Cys, Cys-OEt, and Boc-Cys) $\times 2$ coefficients (a and b)]. Ellipses represent confidence intervals $\pm 1 \mathrm{SD}$ for the individual analytes. 


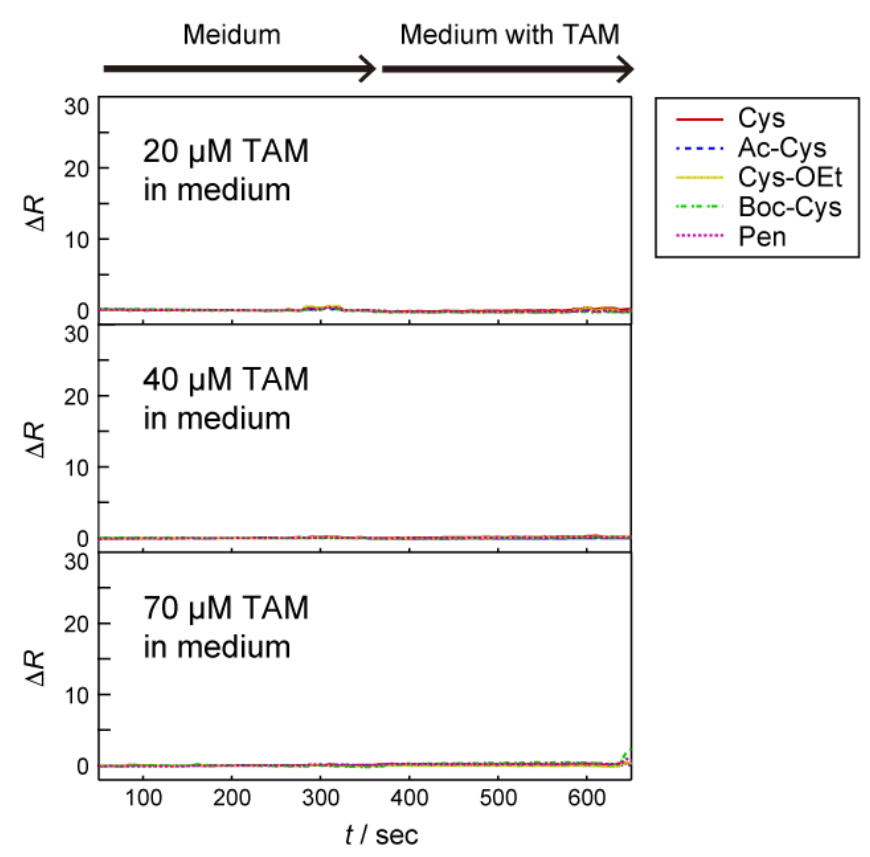

Figure S6. SPR sensorgrams obtained from an inflow of 20-70 $\mu \mathrm{M}$ of TAM-containing media into a chip at a flow rate $5.0 \mu \mathrm{L} / \mathrm{min}$ for $5 \mathrm{~min}$.

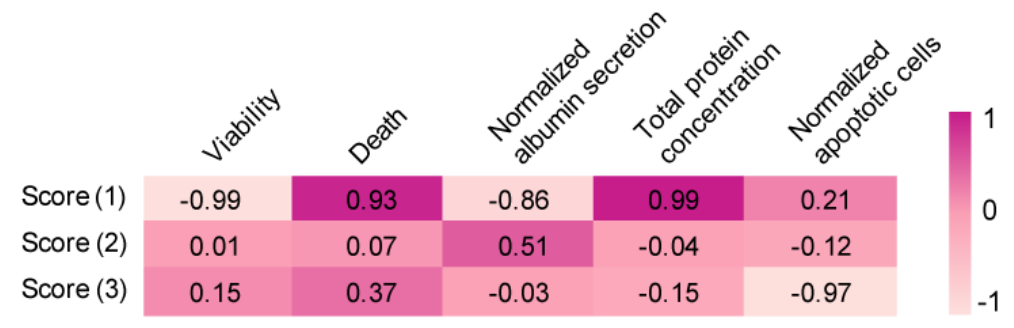

Figure S7. Correlation coefficients between discriminant scores and cell-based assays. The values indicate correlation coefficients. 
Table S1. Dataset of the SPR response patterns obtained from the sensing of five types of cell culture media.

\begin{tabular}{|c|c|c|c|c|c|c|c|c|c|c|}
\hline \multirow{3}{*}{ Analytes } & \multicolumn{10}{|c|}{ SPR responses } \\
\hline & \multicolumn{5}{|c|}{$\mathbf{a} \times \mathbf{1 0}$} & \multicolumn{5}{|c|}{$\mathrm{b} \times 10^{-2}$} \\
\hline & Cys & Ac-Cys & Cys-OEt & Boc-Cys & Pen & Cys & Ac-Cys & Cys-OEt & Boc-Cys & Pen \\
\hline $\mathrm{HeLa}$ & 1.449 & 1.340 & 1.345 & 1.173 & 1.622 & 0.691 & 0.522 & 1.374 & 0.982 & 0.755 \\
\hline HeLa & 1.713 & 1.566 & 1.107 & 1.070 & 1.552 & 0.400 & 0.316 & 1.091 & 1.052 & 0.576 \\
\hline $\mathrm{HeLa}$ & 1.426 & 1.227 & 0.973 & 1.046 & 1.489 & 0.588 & 0.464 & 1.041 & 1.145 & 0.642 \\
\hline $\mathrm{HeLa}$ & 1.506 & 1.391 & 1.204 & 1.053 & 1.386 & 0.519 & 0.401 & 1.388 & 1.064 & 0.626 \\
\hline HeLa & 1.481 & 1.307 & 1.100 & 0.925 & 1.421 & 0.577 & 0.468 & 1.143 & 1.073 & 0.651 \\
\hline $\mathrm{HeLa}$ & 1.430 & 1.252 & 1.331 & 1.317 & 1.548 & 0.644 & 0.595 & 1.419 & 1.289 & 0.802 \\
\hline $\mathrm{HeLa}$ & 1.493 & 1.380 & 1.416 & 1.323 & 1.717 & 0.748 & 0.550 & 1.181 & 1.082 & 0.679 \\
\hline $\mathrm{HeLa}$ & 1.421 & 1.224 & 1.390 & 1.238 & 1.580 & 0.706 & 0.617 & 1.294 & 1.207 & 0.756 \\
\hline $\mathrm{HeLa}$ & 1.442 & 1.348 & 1.421 & 1.294 & 1.660 & 0.778 & 0.535 & 1.036 & 1.085 & 0.721 \\
\hline HeLa & 1.490 & 1.319 & 1.436 & 1.432 & 1.606 & 0.773 & 0.581 & 1.073 & 1.365 & 0.798 \\
\hline TIG1 & 2.018 & 2.245 & 0.959 & 1.199 & 0.704 & 1.290 & 0.979 & 2.010 & 2.309 & 2.436 \\
\hline TIG1 & 1.736 & 2.314 & 0.934 & 1.288 & 0.582 & 0.816 & 0.474 & 0.869 & 1.147 & 0.593 \\
\hline TIG1 & 1.781 & 2.126 & 0.988 & 1.191 & 0.566 & 0.858 & 0.517 & 0.888 & 1.145 & 0.751 \\
\hline TIG1 & 1.899 & 2.298 & 0.917 & 1.310 & 0.489 & 0.875 & 0.495 & 0.925 & 1.157 & 0.776 \\
\hline TIG1 & 1.919 & 2.395 & 1.066 & 1.238 & 0.611 & 0.825 & 0.492 & 1.077 & 1.216 & 0.935 \\
\hline TIG1 & 2.102 & 2.286 & 0.996 & 1.581 & 1.107 & 0.742 & 0.586 & 0.823 & 1.059 & 0.686 \\
\hline TIG1 & 2.032 & 2.233 & 1.396 & 1.655 & 0.921 & 0.869 & 0.572 & 0.885 & 1.079 & 0.728 \\
\hline TIG1 & 2.053 & 2.229 & 1.287 & 1.528 & 1.028 & 0.890 & 0.617 & 0.928 & 1.156 & 0.815 \\
\hline TIG1 & 2.083 & 2.231 & 1.323 & 1.564 & 1.090 & 0.879 & 0.614 & 0.962 & 1.218 & 0.903 \\
\hline TIG1 & 1.935 & 2.093 & 0.846 & 1.209 & 0.545 & 0.999 & 0.681 & 0.939 & 1.223 & 0.729 \\
\hline A431 & 1.061 & 0.763 & 1.424 & 1.076 & 1.319 & 0.522 & 0.500 & 0.833 & 0.789 & 0.558 \\
\hline A431 & 1.317 & 0.910 & 1.372 & 1.065 & 1.421 & 0.282 & 0.324 & 0.837 & 0.731 & 0.444 \\
\hline A431 & 1.363 & 0.875 & 1.099 & 0.784 & 1.185 & 0.384 & 0.408 & 0.870 & 0.948 & 0.468 \\
\hline A431 & 1.795 & 1.119 & 1.238 & 1.017 & 1.583 & 0.275 & 0.343 & 0.800 & 0.802 & 0.480 \\
\hline A431 & 1.697 & 1.179 & 1.240 & 1.078 & 1.168 & 0.406 & 0.439 & 0.888 & 0.838 & 0.611 \\
\hline A431 & 1.464 & 1.040 & 1.376 & 1.113 & 1.382 & 0.452 & 0.481 & 0.943 & 0.987 & 0.611 \\
\hline A431 & 1.659 & 1.091 & 1.304 & 1.039 & 1.349 & 0.409 & 0.454 & 0.891 & 1.034 & 0.549 \\
\hline A431 & 1.720 & 1.278 & 1.185 & 1.035 & 1.461 & 0.324 & 0.340 & 0.974 & 1.077 & 0.579 \\
\hline A 431 & 1.699 & 1.128 & 1.362 & 1.122 & 1.478 & 0.334 & 0.388 & 1.062 & 1.030 & 0.568 \\
\hline A431 & 1.547 & 1.028 & 1.345 & 1.216 & 1.417 & 0.412 & 0.421 & 1.126 & 1.173 & 0.725 \\
\hline $\mathrm{HuH7}$ & 2.793 & 2.500 & 0.974 & 0.900 & 0.968 & 0.469 & 0.340 & 1.317 & 1.077 & 0.727 \\
\hline $\mathrm{HuH7}$ & 3.894 & 2.858 & 1.411 & 1.005 & 1.437 & 0.262 & 0.231 & 1.036 & 0.831 & 0.496 \\
\hline $\mathrm{HuH7}$ & 3.238 & 2.413 & 1.563 & 1.094 & 1.602 & 0.390 & 0.311 & 1.322 & 0.894 & 0.663 \\
\hline $\mathrm{HuH7}$ & 3.412 & 2.240 & 1.708 & 1.263 & 1.397 & 0.334 & 0.367 & 1.263 & 0.986 & 0.661 \\
\hline $\mathrm{HuH7}$ & 4.239 & 3.139 & 1.442 & 1.061 & 1.434 & 0.240 & 0.192 & 0.988 & 0.854 & 0.565 \\
\hline HuH7 & 2.942 & 2.399 & 1.554 & 1.071 & 1.160 & 0.174 & 0.141 & 0.375 & 0.369 & 0.357 \\
\hline $\mathrm{HuH7}$ & 4.966 & 4.639 & 1.595 & 1.156 & 1.828 & 0.180 & 0.118 & 0.977 & 0.595 & 0.530 \\
\hline $\mathrm{HuH7}$ & 3.863 & 3.174 & 1.622 & 1.314 & 1.686 & 0.260 & 0.199 & 1.052 & 0.687 & 0.531 \\
\hline $\mathrm{HuH7}$ & 3.939 & 2.989 & 1.633 & 1.345 & 1.674 & 0.238 & 0.198 & 1.029 & 0.768 & 0.492 \\
\hline HuH7 & 3.536 & 2.277 & 1.603 & 1.355 & 1.620 & 0.286 & 0.286 & 1.115 & 0.725 & 0.409 \\
\hline HepG2 & 2.031 & 1.824 & 1.659 & 1.558 & 2.080 & 1.515 & 1.110 & 1.441 & 0.961 & 0.986 \\
\hline HepG2 & 2.041 & 1.895 & 1.561 & 1.414 & 2.118 & 1.365 & 0.952 & 1.663 & 0.990 & 0.889 \\
\hline HepG2 & 2.230 & 2.092 & 1.786 & 1.784 & 2.227 & 1.526 & 0.966 & 1.297 & 1.145 & 1.048 \\
\hline HepG2 & 2.032 & 2.002 & 1.723 & 1.754 & 2.257 & 1.409 & 0.828 & 1.412 & 1.138 & 0.707 \\
\hline HepG2 & 2.006 & 1.835 & 1.626 & 1.657 & 2.311 & 1.251 & 0.757 & 1.194 & 0.873 & 0.526 \\
\hline HepG2 & 2.011 & 1.933 & 1.727 & 1.665 & 2.137 & 1.541 & 0.859 & 1.195 & 1.059 & 0.810 \\
\hline HepG2 & 1.930 & 2.000 & 1.728 & 1.649 & 1.691 & 1.524 & 0.904 & 1.031 & 1.017 & 1.005 \\
\hline HepG2 & 2.090 & 1.906 & 1.800 & 1.721 & 2.195 & 1.522 & 1.152 & 2.050 & 1.209 & 1.117 \\
\hline HepG2 & 2.008 & 1.887 & 1.615 & 1.656 & 2.407 & 1.304 & 0.802 & 1.497 & 0.791 & 0.658 \\
\hline HepG2 & 2.009 & 1.909 & 1.656 & 1.798 & 2.054 & 1.452 & 0.863 & 1.185 & 0.943 & 0.500 \\
\hline
\end{tabular}


Table S2. Number of combinations achieving each identification accuracy in the sensing of five types of cell culture media.

\begin{tabular}{|c|c|}
\hline Identification accuracy & Number of combinations \\
\hline $100 \%(50 / 50$ samples $)$ & 18 \\
\hline $98 \%$ (49/50 samples) & 123 \\
\hline $96 \%$ (48/50 samples) & 225 \\
\hline $94 \%$ (47/50 samples) & 207 \\
\hline $92 \%$ (46/50 samples) & 140 \\
\hline $90 \%$ (45/50 samples) & 72 \\
\hline $88 \%$ (44/50 samples) & 44 \\
\hline $86 \%$ (43/50 samples) & 36 \\
\hline $84 \%$ (42/50 samples) & 27 \\
\hline $82 \%(41 / 50$ samples $)$ & 25 \\
\hline $80 \%$ (40/50 samples) & 24 \\
\hline $78 \%$ (39/50 samples) & 10 \\
\hline $76 \%$ (38/50 samples) & 12 \\
\hline $74 \%$ (37/50 samples) & 10 \\
\hline $72 \%$ (36/50 samples) & 3 \\
\hline $70 \%$ (35/50 samples) & 5 \\
\hline $68 \%$ (34/50 samples) & 7 \\
\hline $66 \%$ (33/50 samples) & 5 \\
\hline $64 \%(32 / 50$ samples $)$ & 7 \\
\hline $62 \%(31 / 50$ samples $)$ & 4 \\
\hline $60 \%$ (30/50 samples) & 2 \\
\hline $58 \%(29 / 50$ samples $)$ & 2 \\
\hline $56 \%(28 / 50$ samples $)$ & 2 \\
\hline $54 \%(27 / 50$ samples $)$ & 1 \\
\hline $48 \%$ (24/50 samples) & 1 \\
\hline $46 \%$ (23/50 samples) & 1 \\
\hline
\end{tabular}

Table S3. Eighteen combinations of experimental values achieving an identification accuracy of $100 \%$ in the sensing of five types of cell culture media.

\begin{tabular}{|c|c|c|c|c|c|c|c|c|c|c|}
\hline \multirow{3}{*}{ Combination } & \multicolumn{10}{|c|}{ Experimental values } \\
\hline & \multicolumn{5}{|c|}{$\mathbf{a}$} & \multicolumn{5}{|c|}{ b } \\
\hline & Cys & Ac-Cys & Cys-OEt & Boc-Cys & Pen & Cys & Ac-Cys & Cys-OEt & Boc-Cys & Pen \\
\hline \multicolumn{11}{|l|}{$8-1$} \\
\hline \multicolumn{11}{|l|}{$7-1$} \\
\hline \multicolumn{11}{|l|}{$7-2$} \\
\hline \multicolumn{11}{|l|}{$7-3$} \\
\hline \multicolumn{11}{|l|}{$7-4$} \\
\hline \multicolumn{11}{|l|}{$7-5$} \\
\hline \multicolumn{11}{|l|}{$6-1$} \\
\hline \multicolumn{11}{|l|}{$6-2$} \\
\hline \multicolumn{11}{|l|}{$6-3$} \\
\hline \multicolumn{11}{|l|}{$6-4$} \\
\hline \multicolumn{11}{|l|}{$6-5$} \\
\hline \multicolumn{11}{|l|}{$6-6$} \\
\hline \multicolumn{11}{|l|}{$6-7$} \\
\hline \multicolumn{11}{|l|}{$5-1$} \\
\hline \multicolumn{11}{|l|}{$5-2$} \\
\hline $5-3$ & & & & & & & & & & \\
\hline
\end{tabular}


Table S4. Dataset of the SPR response patterns obtained from the sensing of culture media from TAM-treated HepG2 cells. The three columns on the right shows the training data (denoted by "-_) and the test data with the results of the verification by the holdout test.

\begin{tabular}{|c|c|c|c|c|c|c|c|c|c|c|c|c|c|}
\hline \multirow{3}{*}{ Analytes" } & \multicolumn{10}{|c|}{ SPR responses } & \multicolumn{3}{|c|}{ Holdout test } \\
\hline & \multicolumn{5}{|c|}{$\mathbf{a} \times 10$} & \multicolumn{5}{|c|}{$\mathrm{b} \times 10^{-2}$} & \multirow[b]{2}{*}{ Classes } & \multirow[b]{2}{*}{ Verification } & \multirow[b]{2}{*}{ Accuracy } \\
\hline & Cys & Ac-Cys & Cys-OEt & Boc-Cys & Pen & Cys & Ac-Cys & Cys-OEt & Boc-Cys & Pen & & & \\
\hline $0 \mu \mathrm{M} \_0.5 \mathrm{~h}$ & 2.435 & 2.110 & 1.567 & 1.314 & 1.642 & 0.440 & 0.366 & 0.893 & 0.851 & 0.557 & A & - & - \\
\hline $0 \mu \mathrm{M} \_0.5 \mathrm{~h}$ & 2.487 & 1.974 & 1.374 & 1.186 & 1.385 & 0.477 & 0.366 & 0.803 & 0.659 & 0.452 & A & - & - \\
\hline $0 \mu \mathrm{M} \_0.5 \mathrm{~h}$ & 2.092 & 1.795 & 1.262 & 1.301 & 1.891 & 0.527 & 0.306 & 0.575 & 0.702 & 0.392 & A & - & - \\
\hline $0 \mu \mathrm{M} \_0.5 \mathrm{~h}$ & 2.058 & 1.931 & 1.250 & 1.127 & 1.559 & 0.577 & 0.316 & 0.429 & 0.676 & 0.454 & A & - & - \\
\hline $0 \mu \mathrm{M} \_0.5 \mathrm{~h}$ & 2.352 & 1.871 & 1.191 & 0.946 & 1.028 & 0.432 & 0.298 & 0.650 & 0.722 & 0.588 & $\mathrm{~A}$ & - & - \\
\hline $0 \mu \mathrm{M} \_2 \mathrm{~h}$ & 2.186 & 1.926 & 1.233 & 0.926 & 1.300 & 0.507 & 0.326 & 0.666 & 0.738 & 0.394 & A & A & Yes \\
\hline $0 \mu \mathrm{M} \_2 \mathrm{~h}$ & 2.382 & 2.220 & 1.473 & 1.048 & 1.816 & 0.499 & 0.287 & 0.353 & 0.636 & 0.559 & A & A & Yes \\
\hline $0 \mu \mathrm{M} \_2 \mathrm{~h}$ & 2.387 & 1.862 & 1.449 & 1.248 & 1.440 & 0.370 & 0.297 & 0.862 & 0.651 & 0.541 & A & A & Yes \\
\hline $0 \mu \mathrm{M} \_2 \mathrm{~h}$ & 2.448 & 2.075 & 1.486 & 1.183 & 1.738 & 0.441 & 0.328 & 0.943 & 0.660 & 0.455 & A & A & Yes \\
\hline $0 \mu \mathrm{M} \_2 \mathrm{~h}$ & 2.204 & 1.793 & 1.314 & 1.161 & 1.703 & 0.503 & 0.377 & 0.591 & 0.717 & 0.504 & A & A & Yes \\
\hline $\begin{array}{c}20 \mu \mathrm{M} \_0.5 \\
\mathrm{~h}\end{array}$ & 2.203 & 1.845 & 1.414 & 1.214 & 1.796 & 0.419 & 0.314 & 0.623 & 0.468 & 0.378 & A & A & Yes \\
\hline $\begin{array}{c}20 \mu \mathrm{M} \_0.5 \\
\mathrm{~h}\end{array}$ & 2.486 & 2.226 & 1.410 & 1.064 & 1.902 & 0.357 & 0.246 & 0.736 & 0.355 & 0.403 & A & A & Yes \\
\hline $\begin{array}{c}20 \mu \mathrm{M} \_0.5 \\
\mathrm{~h}\end{array}$ & 2.345 & 1.855 & 1.468 & 1.260 & 1.972 & 0.437 & 0.339 & 0.674 & 0.637 & 0.258 & A & A & Yes \\
\hline $\begin{array}{c}20 \mu \mathrm{M} \_0.5 \\
\mathrm{~h}\end{array}$ & 2.209 & 1.861 & 1.332 & 0.908 & 1.500 & 0.440 & 0.317 & 0.724 & 0.545 & 0.518 & A & A & Yes \\
\hline $\begin{array}{c}20 \mu \mathrm{M} \_0.5 \\
\mathrm{~h}\end{array}$ & 2.224 & 1.945 & 1.430 & 1.247 & 1.910 & 0.395 & 0.236 & 0.742 & 0.519 & 0.342 & A & A & Yes \\
\hline $20 \mu \mathrm{M} \_6 \mathrm{~h}$ & 1.948 & 1.761 & 1.595 & 1.989 & 1.802 & 0.702 & 0.492 & 0.856 & 0.470 & 0.573 & B & - & - \\
\hline $20 \mu \mathrm{M} \_6 \mathrm{~h}$ & 2.106 & 2.684 & 1.557 & 1.419 & 1.508 & 0.456 & 0.174 & 0.616 & 0.574 & 0.449 & $\mathrm{~B}$ & - & - \\
\hline $20 \mu \mathrm{M} \_6 \mathrm{~h}$ & 1.962 & 1.989 & 1.463 & 1.551 & 1.750 & 0.675 & 0.409 & 0.913 & 0.767 & 0.725 & B & - & - \\
\hline $20 \mu \mathrm{M} \_6 \mathrm{~h}$ & 2.048 & 1.987 & 1.513 & 1.666 & 1.817 & 0.640 & 0.382 & 0.655 & 0.852 & 0.599 & B & - & - \\
\hline $20 \mu \mathrm{M} \_6 \mathrm{~h}$ & 2.068 & 3.870 & 1.432 & 1.509 & 1.936 & 0.461 & 0.114 & 0.671 & 0.315 & 0.399 & B & - & - \\
\hline $20 \mu \mathrm{M} \_12 \mathrm{~h}$ & 2.357 & 2.207 & 1.626 & 1.386 & 2.004 & 0.696 & 0.483 & 1.037 & 0.907 & 0.750 & B & B & Yes \\
\hline $20 \mu \mathrm{M} \_12 \mathrm{~h}$ & 2.107 & 2.074 & 1.710 & 1.379 & 1.806 & 0.924 & 0.555 & 1.188 & 0.974 & 0.803 & $\mathrm{~B}$ & B & Yes \\
\hline $20 \mu \mathrm{M} \_12 \mathrm{~h}$ & 2.321 & 1.995 & 1.714 & 1.347 & 2.053 & 0.691 & 0.471 & 1.134 & 0.697 & 0.596 & B & B & Yes \\
\hline $20 \mu \mathrm{M} \_12 \mathrm{~h}$ & 2.189 & 1.951 & 1.584 & 1.344 & 1.953 & 0.643 & 0.466 & 1.084 & 0.762 & 0.632 & $\mathrm{~B}$ & B & Yes \\
\hline $20 \mu \mathrm{M} \_12 \mathrm{~h}$ & 2.299 & 1.967 & 1.666 & 1.320 & 1.999 & 0.785 & 0.637 & 1.214 & 0.996 & 0.812 & B & B & Yes \\
\hline $40 \mu \mathrm{M} \_2 \mathrm{~h}$ & 2.287 & 2.253 & 1.673 & 1.461 & 1.725 & 0.436 & 0.224 & 0.547 & 0.505 & 0.531 & B & B & Yes \\
\hline $40 \mu \mathrm{M} \_2 \mathrm{~h}$ & 2.576 & 3.784 & 1.807 & 1.607 & 2.154 & 0.372 & 0.142 & 0.560 & 0.470 & 0.447 & $\mathrm{~B}$ & B & Yes \\
\hline $40 \mu \mathrm{M} \_2 \mathrm{~h}$ & 1.977 & 2.215 & 1.521 & 1.369 & 1.667 & 0.561 & 0.251 & 0.451 & 0.540 & 0.502 & B & B & Yes \\
\hline $40 \mu \mathrm{M} \_2 \mathrm{~h}$ & 2.177 & 2.109 & 1.505 & 1.402 & 1.756 & 0.499 & 0.288 & 0.702 & 0.592 & 0.619 & B & B & Yes \\
\hline $40 \mu \mathrm{M} \_2 \mathrm{~h}$ & 1.992 & 1.720 & 1.694 & 1.691 & 1.760 & 0.450 & 0.279 & 0.438 & 0.289 & 0.415 & B & B & Yes \\
\hline $70 \mu \mathrm{M} \_2 \mathrm{~h}$ & 2.170 & 2.093 & 1.720 & 1.502 & 2.016 & 1.566 & 1.134 & 1.930 & 2.005 & 1.510 & $\mathrm{C}$ & - & - \\
\hline $70 \mu \mathrm{M} \_2 \mathrm{~h}$ & 2.334 & 2.180 & 1.764 & 1.715 & 2.246 & 1.425 & 1.098 & 1.900 & 1.635 & 1.087 & $\mathrm{C}$ & - & - \\
\hline $70 \mu \mathrm{M} \_2 \mathrm{~h}$ & 2.142 & 2.037 & 1.524 & 1.175 & 2.026 & 1.523 & 1.046 & 1.747 & 1.169 & 1.342 & $\mathrm{C}$ & - & - \\
\hline $70 \mu \mathrm{M} \_2 \mathrm{~h}$ & 2.116 & 1.930 & 1.605 & 1.805 & 2.112 & 1.724 & 1.166 & 1.930 & 2.192 & 1.338 & $\mathrm{C}$ & - & - \\
\hline $70 \mu \mathrm{M} \_2 \mathrm{~h}$ & 2.300 & 2.216 & 1.414 & 1.790 & 1.758 & 1.631 & 1.123 & 1.010 & 1.644 & 1.696 & $\mathrm{C}$ & - & - \\
\hline $40 \mu \mathrm{M} \_12 \mathrm{~h}$ & 2.580 & 2.384 & 2.048 & 1.592 & 2.254 & 1.387 & 0.984 & 2.131 & 1.589 & 1.230 & $\mathrm{C}$ & $\mathrm{C}$ & Yes \\
\hline $40 \mu \mathrm{M} \_12 \mathrm{~h}$ & 2.539 & 2.278 & 1.797 & 1.419 & 2.069 & 0.855 & 0.623 & 1.349 & 0.866 & 0.826 & $\mathrm{C}$ & $\mathrm{C}$ & Yes \\
\hline $40 \mu \mathrm{M} \_12 \mathrm{~h}$ & 2.545 & 2.323 & 1.859 & 1.715 & 2.134 & 1.893 & 1.305 & 2.388 & 1.932 & 1.830 & $\mathrm{C}$ & $\mathrm{D}$ & No \\
\hline $40 \mu \mathrm{M} \_12 \mathrm{~h}$ & 2.457 & 2.315 & 1.768 & 1.734 & 2.008 & 1.345 & 0.881 & 1.884 & 1.722 & 1.410 & $\mathrm{C}$ & $\mathrm{C}$ & Yes \\
\hline
\end{tabular}




\begin{tabular}{|c|c|c|c|c|c|c|c|c|c|c|c|c|c|}
\hline $40 \mu \mathrm{M} \_12 \mathrm{~h}$ & 2.681 & 2.613 & 1.895 & 1.645 & 2.442 & 1.406 & 0.967 & 1.764 & 1.814 & 1.238 & $\mathrm{C}$ & $\mathrm{C}$ & Yes \\
\hline $70 \mu \mathrm{M} \_12 \mathrm{~h}$ & 2.670 & 2.712 & 1.903 & 1.863 & 2.586 & 2.116 & 1.653 & 2.310 & 2.424 & 1.566 & D & - & - \\
\hline $70 \mu \mathrm{M} \_12 \mathrm{~h}$ & 2.777 & 2.657 & 1.923 & 1.718 & 2.728 & 2.138 & 1.654 & 2.546 & 2.435 & 1.610 & D & - & - \\
\hline $70 \mu \mathrm{M} \_12 \mathrm{~h}$ & 2.811 & 2.662 & 2.016 & 1.830 & 2.616 & 1.835 & 1.424 & 2.308 & 2.203 & 1.513 & D & - & - \\
\hline $70 \mu \mathrm{M} \_12 \mathrm{~h}$ & 2.801 & 2.767 & 2.099 & 1.873 & 2.756 & 2.026 & 1.641 & 2.382 & 2.272 & 1.573 & D & - & - \\
\hline $70 \mu \mathrm{M} \_12 \mathrm{~h}$ & 2.485 & 2.587 & 1.989 & 1.501 & 2.401 & 2.009 & 1.483 & 2.158 & 1.651 & 1.445 & D & - & - \\
\hline $70 \mu \mathrm{M} \_6 \mathrm{~h}$ & 2.709 & 2.636 & 2.056 & 1.638 & 2.505 & 2.165 & 1.707 & 2.296 & 1.835 & 1.607 & D & $\mathrm{D}$ & Yes \\
\hline $70 \mu \mathrm{M} \_6 \mathrm{~h}$ & 2.774 & 2.640 & 2.121 & 1.842 & 2.386 & 2.052 & 1.439 & 2.775 & 2.414 & 1.913 & D & $\mathrm{D}$ & Yes \\
\hline $70 \mu \mathrm{M} \_6 \mathrm{~h}$ & 2.789 & 2.663 & 2.138 & 1.986 & 2.756 & 2.147 & 1.619 & 2.492 & 2.431 & 1.455 & D & $\mathrm{D}$ & Yes \\
\hline $70 \mu \mathrm{M} \_6 \mathrm{~h}$ & 2.534 & 2.588 & 2.048 & 1.784 & 2.304 & 2.179 & 1.565 & 2.762 & 2.308 & 1.650 & D & $\mathrm{D}$ & Yes \\
\hline $70 \mu \mathrm{M} \_6 \mathrm{~h}$ & 2.398 & 2.338 & 1.779 & 1.722 & 2.352 & 1.838 & 1.394 & 2.437 & 2.141 & 1.639 & D & $\mathrm{C}$ & No \\
\hline
\end{tabular}

Table S5. Number of combinations achieving each identification accuracy in the sensing of culture media from TAM-treated HepG2 cells.

\begin{tabular}{cc}
\hline Identification accuracy & Number of combinations \\
\hline $100 \%$ (20/20 samples) & 165 \\
$95 \%(19 / 20$ samples $)$ & 292 \\
$90 \%(18 / 20$ samples $)$ & 194 \\
$85 \%(17 / 20$ samples $)$ & 168 \\
$80 \%(16 / 20$ samples $)$ & 111 \\
$75 \%(15 / 20$ samples $)$ & 49 \\
$70 \%(14 / 20$ samples $)$ & 19 \\
$65 \%(13 / 20$ samples $)$ & 4 \\
$60 \%(12 / 20$ samples $)$ & 11 \\
\hline
\end{tabular}




\section{Supplementary note: General cell-based assays}

Experimental procedures. All absorbance and fluorescence intensities were recorded on a Cytation5 Imaging Reader (BioTek Instruments, Inc., Winooski, VT, USA).

Determination of cell viability by WST-8 assay. The cells on the microplate were washed with DPBS (100 $\mu \mathrm{L})$, before fresh $\mathrm{CDCHO}+(100 \mu \mathrm{L})$ and working reagent [10 $\mu \mathrm{L}$; Cell Counting Kit-8 (Dojindo Molecular Technologies, Inc., Kumamoto, Japan)] were added to the wells. After incubation for $3 \mathrm{~h}$, stop solution $[10 \mu \mathrm{L} ; 10 \mathrm{mg} / \mathrm{mL}$ sodium dodecyl sulfate] was added. The cell viability (\%) was calculated based on absorbance at $450 \mathrm{~nm}\left(\mathrm{Abs}_{450}\right)$ according to:

$$
\text { Viability } \%=\frac{\operatorname{Abs}_{450}(\text { sample })-\mathrm{Abs}_{450}(\text { blank })}{\operatorname{Abs}_{450}(\text { control })-\mathrm{Abs}_{450}(\text { blank })} \times 100
$$

where the cell viability (\%) of the cells untreated with TAM was considered as $100 \%$.

Determination of cell death by LDH leakage assay. Only the well for the positive control was treated with lysis solution $(20 \mu \mathrm{L})$ and incubated for 30 min prior to assay. The resulting medium supernatant $(15 \mu \mathrm{L})$ of each well was mixed with working reagent [30 $\mu \mathrm{L}$; Cytotoxicity LDH Assay Kit-WST (Dojindo Molecular Technologies, Inc., Kumamoto, Japan)] in a 96-well half-volume plate (Corning, Inc., NY, USA). After incubation at room temperature for 30 min under shading, stop solution $(15 \mu \mathrm{L})$ was added to the mixtures. The cell death $(\%)$ was calculated based on absorbance at $490 \mathrm{~nm}\left(\mathrm{Abs}_{490}\right)$ according to:

$$
\text { Death } \%=\frac{\mathrm{Abs}_{490}(\text { sample })-\mathrm{Abs}_{490}(\text { negative control })}{\mathrm{Abs}_{490}(\text { positive control })-\mathrm{Abs}_{490}(\text { negative control })} \times 100
$$

where the cell death (\%) of the cells treated with lysis solution was considered as $100 \%$.

Quantification of human serum albumin (HSA) by enzyme-linked immunosorbent assay (ELISA). Human albumin ELISA quantitation set (Bethyl Laboratories, Inc., Motgomery, TX, USA) was used. The compositions of solutions for ELISA are as follows: coating buffer [0.05 M carbonate-bicarbonate buffer $(\mathrm{pH}=9.6)]$; DPBS, Dulbecco's phosphate buffered saline without calcium chloride and magnesium chloride $(\mathrm{pH}=7.4)$; PBST [0.05\% Tween20 in DPBS]. In each well of a 96-well microplate (Thermo Fisher Scientific, Inc., Waltham, MA, USA) $10 \mu \mathrm{g} / \mathrm{mL}$ capture antibody in coating buffer $(100 \mu \mathrm{L})$ was deposited. After incubation at $4{ }^{\circ} \mathrm{C}$ overnight, the wells were washed with PBST $(300 \mu \mathrm{L} \times 3)$. Each well was treated with $0.1 \%$ bovine serum albumin (BSA) in DPBS $(200 \mu \mathrm{L})$ and incubated at $37{ }^{\circ} \mathrm{C}$ for $1 \mathrm{~h}$. After washing with PBST $(300 \mu \mathrm{L} \times 3)$, each well was treated with medium supernatant of the analyte or standards in $0.1 \%$ BSA in PBST $(50 \mu \mathrm{L})$. After washing with PBST $(300 \mu \mathrm{L} \times 3)$, each well was then treated with $10 \mu \mathrm{g} / \mathrm{mL}$ detection antibody modified with horseradish peroxidase (HRP) $(100 \mu \mathrm{L})$, incubated at $37^{\circ} \mathrm{C}$ for $1 \mathrm{~h}$, and washed with PBST (300 $\mu \mathrm{L} \times 3)$. Then, $13.3 \mathrm{ng} / \mathrm{mL}$ HRP substrate $(100 \mu \mathrm{L})$ was added to each well, which was incubated for $15 \mathrm{~min}$ at room temperature. After addition of $1 \mathrm{M} \mathrm{HCl}(100 \mu \mathrm{L})$, the concentration of HSA was calculated based on the absorbance at $450 \mathrm{~nm}$ using a calibration curve prepared by an HSA standard solution. 
Quantification of the total protein concentration by a Bradford assay. In a well of a 96-well half-volume plate (Corning, Inc., NY, USA), a mixture of medium supernatant of analyte or standard (7.5 $\mu \mathrm{L}), \mathrm{CDCHO}+(7.5 \mu \mathrm{L})$, working reagent $[170 \mu \mathrm{L}$; Bradford reagent (Sigma-Aldrich, Co., LLC, St. Louis, MO, USA); 2x diluted solution with water] was incubated at 5 min under shading conditions. The total concentration of protein was calculated based on the absorbance at $595 \mathrm{~nm}$ using a calibration curve prepared by a BSA standard solution.

Apoptotic cell detection by caspase-3/7 assay. The cells were washed with DPBS $(100 \mu \mathrm{L})$ and added to CDCHO $+(50$ $\mu \mathrm{L}$ ) and working reagent [50 $\mu \mathrm{L}$; Apo-ONE Homogeneous Caspase-3/7 Assay Kit (Promega Corp., Madison, WI, USA)]. After incubation at room temperature for $3 \mathrm{~h}$, the fluorescence intensities of the reaction mixture were recorded using excitation and emission wavelengths of 499 and $521 \mathrm{~nm}$, respectively. The normalized apoptotic cells were calculated based on fluorescence $\left(\mathrm{FL}_{499 / 521}\right)$ according to:

$$
\text { Normalized apoptotic cells }=\frac{\mathrm{FL}_{499 / 521}(\text { sample })-\mathrm{FL}_{499 / 521}(\text { blank })}{\mathrm{FL}_{499 / 521}(\text { control })-\mathrm{FL}_{499 / 521}(\text { blank })}
$$

where the cells untreated with TAM were considered as 1.

Classification of characteristics of cells according to cell-based assays. The results of cell-based assays of TAM-treated HepG2 cells are summarized in Figure S8. We selected characteristic cases from the assay results under various conditions according to the results of HSA secretion, the incidence of apoptosis, as well as cell viability and cell death, and we classified the states of HepG2 cells after treatment of TAM into four groups, i.e., alive (A), alive/low active (B), apoptotic (C), and dead (D) (Table S8). Cell viability by WST-8 assay and cell death by LDH leakage assay are based on the detection of the amount of mitochondrial dehydrogenase in cells reflecting metabolic activity of cells and the released LDH from inside of cells by disruption of the cell membrane, respectively. ${ }^{1}$ HSA secretion is an indicator of active hepatic cells. One of the function of liver parenchymal cells is to synthesize and secrete human plasma proteins, including $\mathrm{HSA} ;^{2}$ thus, the secretion of HSA from HepG2 cells physiologically means a function as a hepatocellular cells. ${ }^{3}$ A decreased HSA secretion detected by the ELISA-based assay indicates a decreased function as a hepatocyte, which is sometimes resulted from acute-phase reaction by the treatment of chemical compounds on cells. ${ }^{4}$ Apoptotic cells are determined based on the detection of caspase-3/7, a downstream biomarker of apoptosis..$^{5}$ Group A contains cells whose viability and death are almost 100 and $0 \%$, respectively. Group B was assigned to cases in which the HSA secretion was significantly less than that in group A $(p<0.05)$, while cell death was still approximately $0 \%$. Group D contains cells with cell viability and death of $0 \%$ and a saturated value, respectively. Group C contains cellular states between group B and D, where some reduction and increase in cell viability and cell death were observed, respectively, while at the same time marked apoptosis occurred. Group C was therefore named C "apoptotic" (Figure S8f). To discuss the correlation between discriminant scores and the results of the cell-based assays, the total protein concentration was also determined (Figure S8e). In Figure S8g, group A to D of training and test datasets are summarized as bar graphs in order to facilitate the visual interpretation of the differences among each group. 
Table S6. Classification of cell states of TAM-treated HepG2 cells.

\begin{tabular}{|c|c|c|c|}
\hline Group & Training data ${ }^{*}$ & Test data ${ }^{*}$ & Characteristics \\
\hline A (alive) & $0 \mu \mathrm{M} \_0.5 \mathrm{~h}$ & $\begin{array}{l}0 \mu \mathrm{M} \_2 \mathrm{~h} \\
20 \mu \mathrm{M} \_0.5 \mathrm{~h}\end{array}$ & $\begin{array}{l}\cdot \text { Viability } \sim 100 \% \text {; cells are alive } \\
\text { - Death } \sim 0 \% \text {; cells are not dead }\end{array}$ \\
\hline $\begin{array}{l}\mathrm{B} \text { (alive/low } \\
\text { active) }\end{array}$ & $20 \mu \mathrm{M} \_6 \mathrm{~h}$ & $\begin{array}{l}20 \mu \mathrm{M} \_12 \mathrm{~h} \\
40 \mu \mathrm{M} \_2 \mathrm{~h}\end{array}$ & $\begin{array}{l}- \text { Death } \sim 0 \% \text {; cells are not dead } \\
\text { - HSA secretion of group B is significantly }(p<0.05) \text { lower than that of group A; the } \\
\text { ability to produce protein is impaired }\end{array}$ \\
\hline C (apoptotic) & $40 \mu \mathrm{M} \_12 \mathrm{~h}$ & $70 \mu \mathrm{M} \_2 \mathrm{~h}$ & $\begin{array}{l}\text { - Viability: between group B and D } \\
\text { - Death: between group B and D } \\
\text { - Caspase-3/7 activity is markedly higher than in other groups; remarkable apoptosis } \\
\text { occurs }\end{array}$ \\
\hline $\mathrm{D}($ dead $)$ & $70 \mu \mathrm{M} \_12 \mathrm{~h}$ & $70 \mu \mathrm{M} \_6 \mathrm{~h}$ & $\begin{array}{l}\cdot \text { Viability } \sim 0 \% \text {; cells are not alive } \\
\text { - Death } \sim \text { saturated value; cells are dead }\end{array}$ \\
\hline
\end{tabular}

${ }^{*} x \mu \mathrm{M} \_t \mathrm{~h}$ refers to the cell culture medium obtained from HepG2 cells treated with $x \mu \mathrm{M}$ TAM for $t \mathrm{~h}$. 
a

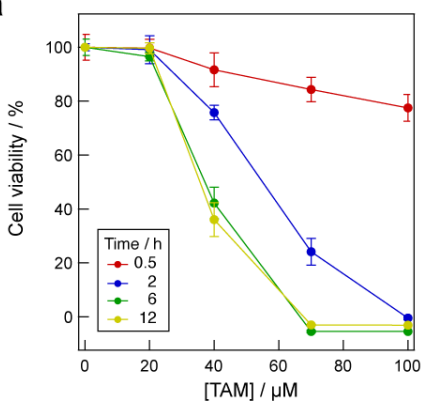

C
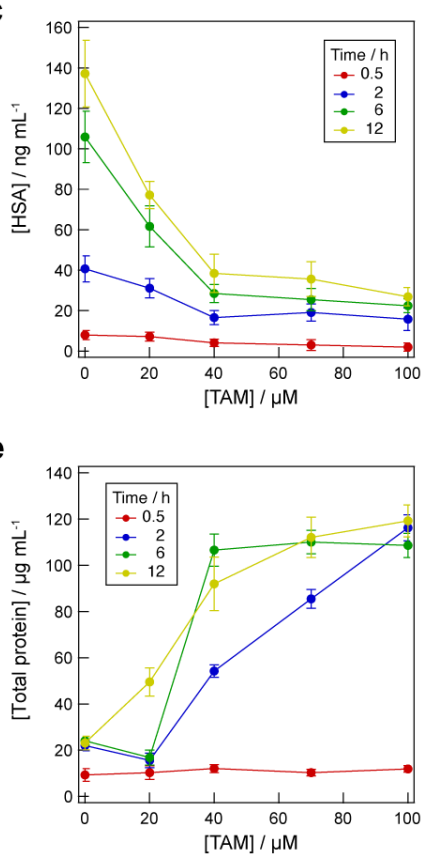

b

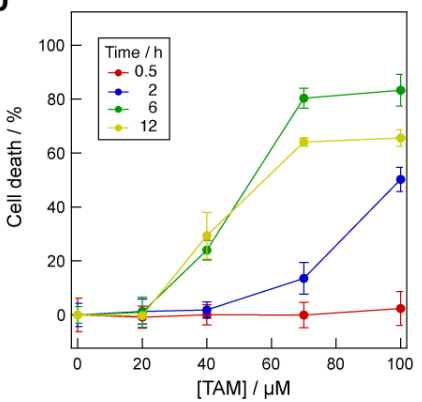

d

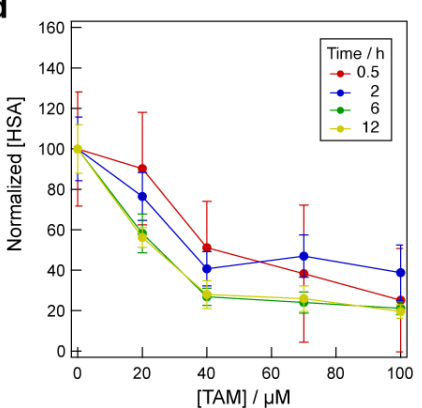

f

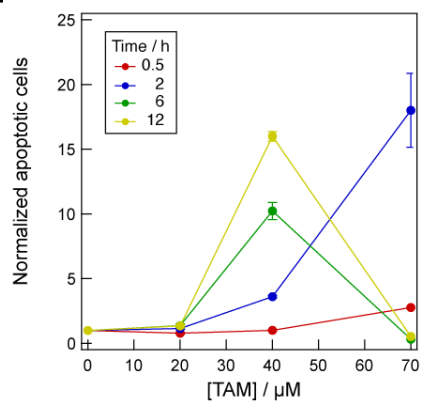

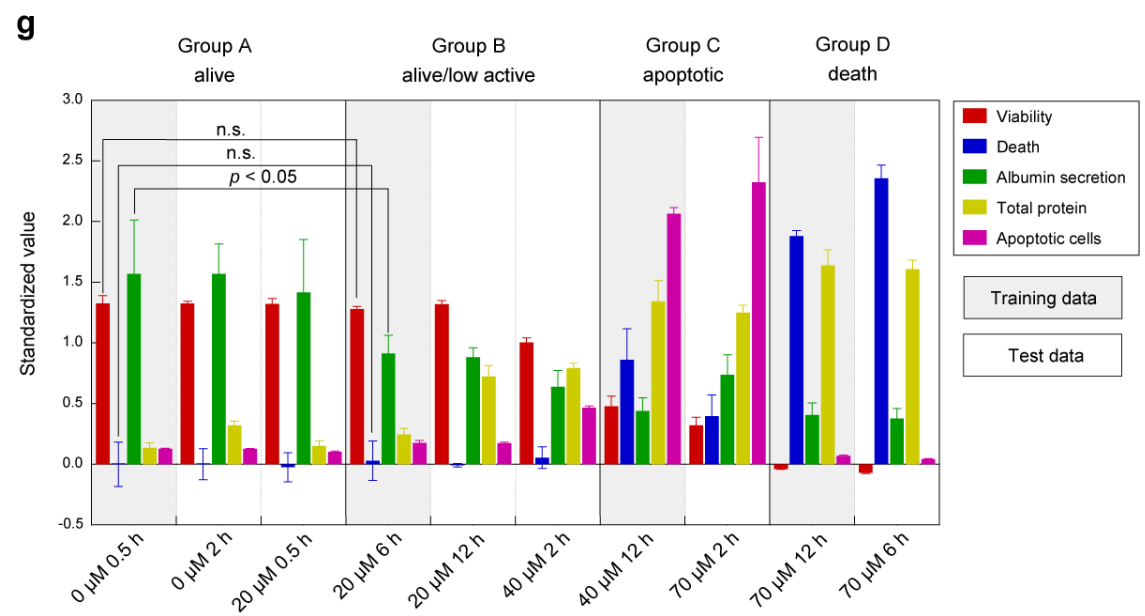

Figure S8. Cell-based assays of TAM-treated HepG2 cells. HepG2 cells were treated with TAM (0-100 $\mu$ M) for 0.5-12 h. (a) Viability. (b) Death. (c) HSA concentration. (d) Normalized HSA concentration. The cells untreated with TAM are normalized as 100. (e) Total protein concentration. (f) Normalized apoptotic cells. Values shown refer to mean values \pm $\mathrm{SD}[n=3$ for (a), (b), and (e); $n=4$ for (c) and (d): $n=6$ for (f)]. (g) Classification of cell states based on the results of independent common biochemical assays. Therein, the vertical axis indicates the values of each biochemical assays [(a), (b), (d), (e), and (f)] that are standardized with the root mean square. 


\section{References}

(1) Aslantürk, Ö. S. In Vitro Cytotoxicity and Cell Viability Assays: Principles, Advantages, and Disadvantages. In Genotoxicity - A Predictable Risk to Our Actual World; Larramendy, M. L., Soloneski, S., Eds.; IntechOpen: Rijeka, 2018.

(2) Knowles, B. B.; Howe, C. C.; Aden, D. P. Human Hepatocellular Carcinoma Cell Lines Secrete the Major Plasma Proteins and Hepatitis B Surface Antigen. Science 1980, 209 (4455), 497-499.

(3) Jeschke, M. G. The Hepatic Response to Thermal Injury: Is the Liver Important for Postburn Outcomes? Mol. Med. 2009, 15 (9), 337-351.

(4) Iwasa, F.; Galbraith, R. A.; Sassa, S. Effects of Dimethyl Sulphoxide on the Synthesis of Plasma Proteins in the Human Hepatoma HepG2. Induction of an Acute-Phase-like Reaction. Biochem. J. 1988, 253 (3), 927-930.

(5) Taylor, R. C.; Cullen, S. P.; Martin, S. J. Apoptosis: Controlled Demolition at the Cellular Level. Nat. Rev. Mol. Cell Biol. 2008, 9 (3), 231-241. 